\title{
NUMERICAL INVESTIGATION OF THE INVERSE PROBLEM FOR THE BOUSSINESQ - LOVE MATHEMATICAL MODEL
}

A. V. Lut, South Ural State University, Chelyabinsk, Russian Federation, lutav@susu.ru

\begin{abstract}
The article is devoted to the numerical investigation of the inverse problem for the Boussinesq - Love mathematical model, which describes longitudinal vibrations in a thin elastic rod taking into account inertia and external load. The inverse problem is understood as the restoration of any coefficient of the original equation, in this case, the function responsible for the external load. To find it, the method of successive approximations was used. The first paragraph presents the previously obtained results of an analytical study of this problem. The second section describes step by step an algorithm for finding an approximate solution. The third paragraph contains the results of computational experiments presented by two examples. The given examples were obtained during the implementation of the developed algorithm in the Maple software package. The results of this work can be used in further research in the field of mathematical physics or mathematical modeling.
\end{abstract}

Keywords: mathematical model; Boussinesq - Love equation; inverse problem; numerical study; Sobolev type equation; method of successive approximations.

\section{Introduction}

Let $\Omega \subset \mathbb{R}^{n}$ be a bounded domain with a boundary $\partial \Omega$ of class $C^{\infty}$. In the cylinder $\Omega \times[0 ; T]$ consider the Boussinesq - Love equation

$$
(\lambda-\Delta) v_{t t}=\alpha\left(\Delta-\lambda^{\prime}\right) v_{t}+\beta\left(\Delta-\lambda^{\prime \prime}\right) v+f q,
$$

with initial conditions

$$
v(x, 0)=v_{0}(x), v_{t}(x, 0)=v_{1}(x)
$$

boundary condition

$$
\left.v(x, t)\right|_{\partial \Omega}=0
$$

and overdetermination condition

$$
\int_{\Omega} v(x, t) K(x) d x=\Phi(t),
$$

where $v_{0}(x), v_{1}(x), K(x), \Phi(t)$ are given functions.

Equation (1) describes longitudinal vibrations in a thin elastic rod, taking into account the inertia and under external load. The coefficients $\lambda, \alpha, \lambda^{\prime}, \beta, \lambda^{\prime \prime}$ characterize the properties of the rod material and relate such quantities as Young's modulus, Poisson's ratio, material density and radius of gyration relative to the center of gravity, in addition, the function $f$ sets a known part of the external load (if known). The first condition in (2) specifies the initial (at time $t=0$ ) state of the rod, and the second sets the initial velocity. The boundary condition (3) fixes the rod ends, that is, there is no longitudinal displacement at the rod ends. The integral overdetermination condition (4) arises at the 
moment when, in addition to finding the function $u$, it is required to restore the component of the external load $q$.

The Boussinesq - Love equation (1) was originally presented in 1935 [1]. This equation is a Sobolev-type equation with respect to the second-order time derivative. Recently a large number of studies have been devoted to Sobolev-type equations. The article [2] presents an overview of the results devoted to optimal control problems for Sobolev-type models with an initial-final condition or the Showalter - Sidorov condition. The article [3] presents sufficient conditions for the existence of positive solutions to the Showalter Sidorov problem, as well as Cauchy for a linear abstract Sobolev type equation. The work [4] became fundamental for this numerical study, as it contains an analytical study of the stated problem, including the theorem on the existence and uniqueness of its solution.

The inverse problem arises when, in addition to finding the function $v(x, t)$, it is also necessary to recover the function $q(t)$ from (1)-(4). Papers [5]-[9] are devoted to the numerical study of inverse and direct problems. The study [5] uses various approaches to solve the inverse problem of the two-dimensional nonstationary convectiondiffusion equation; the results of computational experiments implemented in the Matlab environment are also presented. A numerical study of the problem with non-self-adjoint operators is carried out in [6], continuing the study of the solution of the retrospective inverse problem of heat conduction. The paper [7] proposes one of the effective methods for solving a mathematical dynamic inverse problem, the possibility of its application is discussed, and numerical results are presented. In [8] a boundary value problem for a wave function with a nonlinear asymptotic condition, in which the unknown scattering phase is excluded, is studied reducing it to minimization with respect to the parameters of the functional. The paper [9] is devoted to a numerical study of the modified Boussinesq Love equation defined on a graph.

\section{Analytical Investigation of the Mathematical Model}

Problem (1)-(4) can be reduced to the problem of finding functions $u \in C^{2}\left([0, T] ; \mathcal{U}^{1}\right)$, $w \in C^{2}\left([0, T] ; \mathcal{U}^{0}\right), q \in C^{1}([0, T] ; \mathcal{Y})$ from relations

$$
\begin{gathered}
u^{\prime \prime}(t)=S_{1} u^{\prime}(t)+S_{0} u(t)+\left(A^{1}\right)^{-1} Q \chi(t) q(t)+\left(A^{1}\right)^{-1} Q f(t), \\
u(0)=u_{0}, u^{\prime}(0)=u_{1}, \\
C u(t)=\Psi(t) \equiv C v(t), \\
H_{0} w^{\prime \prime}(t)=H_{1} w^{\prime}(t)+w(t)+\left(B_{0}^{0}\right)^{-1}(\mathbb{I}-Q) \chi(t) q(t)+\left(B_{0}^{0}\right)^{-1}(\mathbb{I}-Q) f(t), \\
w(0)=w_{0}, w^{\prime}(0)=w_{1},
\end{gathered}
$$

where

$$
\begin{gathered}
S_{1}=\sum_{\lambda_{k} \neq \lambda} \frac{\alpha\left(\lambda_{k}-\lambda^{\prime}\right)}{\lambda-\lambda_{k}}<\cdot, \varphi_{k}>\varphi_{k}, \quad S_{0}=\sum_{\lambda_{k} \neq \lambda} \frac{\beta\left(\lambda_{k}-\lambda^{\prime \prime}\right)}{\lambda-\lambda_{k}}<\cdot, \varphi_{k}>\varphi_{k}, \\
u_{0}=\sum_{\lambda_{k} \neq \lambda}<v_{0}, \varphi_{k}>\varphi_{k}, \quad u_{1}=\sum_{\lambda_{k} \neq \lambda}<v_{1}, \varphi_{k}>\varphi_{k} \\
w_{0}=\sum_{\lambda_{k}=\lambda}<v_{0}, \varphi_{k}>\varphi_{k}, \quad w_{1}=\sum_{\lambda_{k}=\lambda}<v_{1}, \varphi_{k}>\varphi_{k}
\end{gathered}
$$




$$
H_{0}=\sum_{\lambda_{k}=\lambda} \frac{\lambda-\lambda_{k}}{\beta\left(\lambda_{k}-\lambda^{\prime \prime}\right)}<\cdot, \varphi_{k}>\varphi_{k}, \quad H_{1}=\sum_{\lambda_{k}=\lambda} \frac{\alpha\left(\lambda_{k}-\lambda^{\prime}\right)}{\beta\left(\lambda_{k}-\lambda^{\prime \prime}\right)}<\cdot, \varphi_{k}>\varphi_{k}, t \in[0, T] .
$$

Here $\left\{\lambda_{k}\right\}=\sigma(\Delta)$ denotes the set of eigenvalues of the Laplace operator, numbered nonincreasingly with regard to multiplicity, and $\left\{\varphi_{k}\right\}$ denotes the family of the corresponding eigenfunctions, orthonormal with respect to the inner product $\langle\cdot, \cdot\rangle$ of $L^{2}(\Omega)$.

Theorem 1. [4] Let one of the conditions $\lambda \notin \sigma(\Delta)$ or $(\lambda \in \sigma(\Delta)) \wedge\left(\lambda=\lambda^{\prime}\right) \wedge\left(\lambda \neq \lambda^{\prime \prime}\right)$ be fulfilled. Let $K, \quad u_{0}, \quad u_{1} \in \mathcal{U}^{1}, \quad f \in C^{2}([0, T] ; \mathcal{L}(\mathcal{Y} ; \mathcal{F})), \Phi \in C^{4}([0, T] ; \mathcal{Y})$, $\sum_{\lambda \neq \lambda_{k}} \frac{\leq f(\cdot, t), K>}{\lambda-\lambda_{k}} \neq 0$, the condition $\int_{\Omega} v_{1}(x) K(x) d x=\Phi^{\prime}(0)$ be satisfied for initial value $v_{1} \in \mathcal{U}^{1}$, and the initial values $w_{m}=(\mathbb{I}-P) v_{m} \in \mathcal{U}^{0}, m=0,1$, satisfy

$$
\begin{gathered}
<w_{0}+\frac{f(\cdot, 0) q(0)}{\beta\left(\lambda_{k}-\lambda^{\prime \prime}\right)}, \varphi_{k}>=0 \text { for } k: \lambda_{k}=\lambda, \\
<w_{1}+\frac{f_{t}(\cdot, 0) q(0)+f(\cdot, 0) q^{\prime}(0)}{\beta\left(\lambda_{k}-\lambda^{\prime \prime}\right)}, \varphi_{k}>=0 \text { for } k: \lambda_{k}=\lambda .
\end{gathered}
$$

Then there exists a unique solution $(v, q)$ of inverse problem (1)-(4), where $q \in C^{2}([0, T] ; \mathcal{Y}), v=u+w$, whence $u \in C^{2}\left([0, T] ; \mathcal{U}^{1}\right)$ is a solution of (5)-(7) and the function $w \in C^{2}\left([0, T] ; \mathcal{U}^{0}\right)$ is a solution of (8)-(9) given by

$$
w(t)=-\sum_{\lambda=\lambda_{k}}<\frac{f(\cdot, t) q(t)}{\beta\left(\lambda_{k}-\lambda^{\prime \prime}\right)}, \varphi_{k}>\varphi_{k} .
$$

\section{Algorithm of Numerical Method}

Let us describe the algorithm developed for the numerical solution of the inverse problem for the Boussinesq - Love equation in steps corresponding to the block diagram presented in Figures 1-3.

Start of the program.

Step 1. Input the parameters of the Boussinesq - Love equation $\lambda, \lambda^{\prime}, \lambda^{\prime \prime}, \alpha, \beta$; the length of the rod $l$; the time limit $T$, the permissible error $E$ for the desired function $q(t)$, the required number $N$ of terms of the Galerkin sum.

Step 2. Input functions: the known part of the external load $f(x, t)$, the initial position of the rod $v_{0}(x)$, the initial velocity $v_{1}(x)$, the kernel $K(x)$ and the righthand side $F(t)$ of the overdetermination condition.

Step 3. Check the fulfillment of the boundary condition for the introduced functions $v_{0}(x)$ and $v_{1}(x)$. If the condition is not met, then go to the next step, otherwise go to step 5.

Step 4. Print "Input another $v_{0}(x), v_{1}(x)$ ". Go to step 2.

Step 5. Solution of the Sturm - Liouville problem.

Step 5.1. Find the general solution of the differential equation from the Sturm Liouville problem.

Step 5.2. Form a system of equations for unknown coefficients obtained from conditions in the Sturm - Liouville problem.

Step 5.3. Calculate the determinant of the resulting system. 


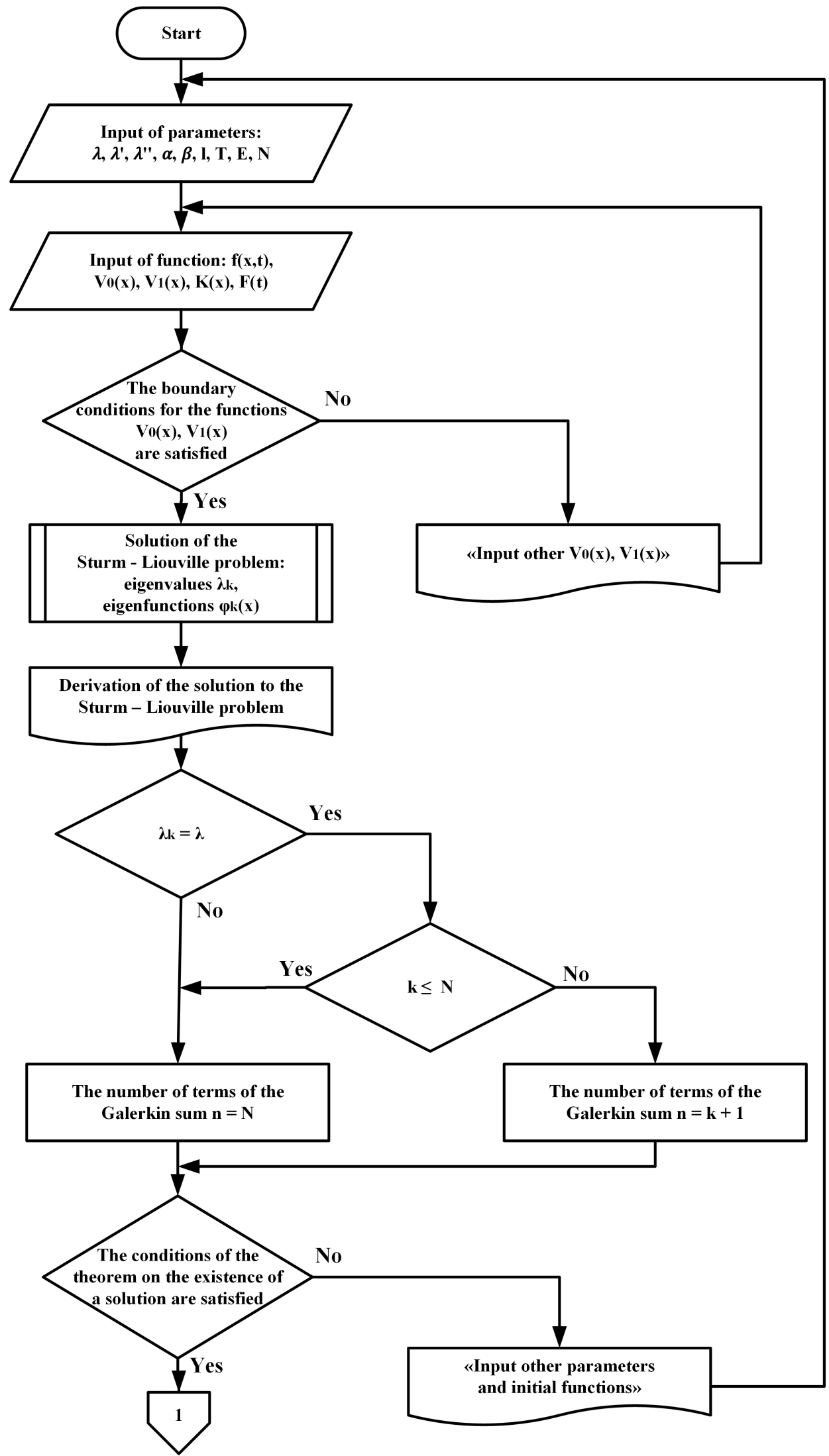

Fig. 1. Diagram of the algorithm - part 1. 


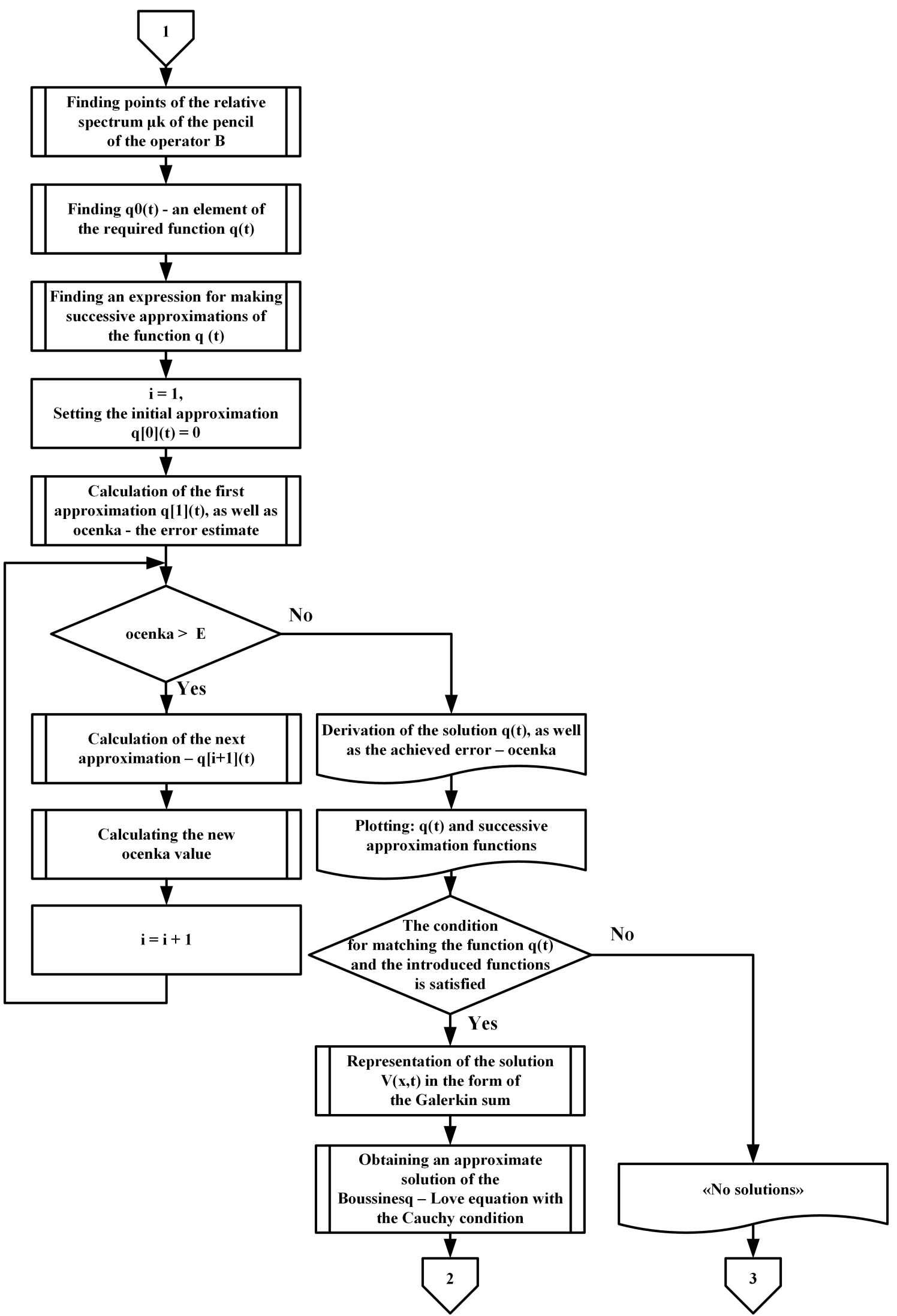

Fig. 2. Diagram of the algorithm - part 2. 


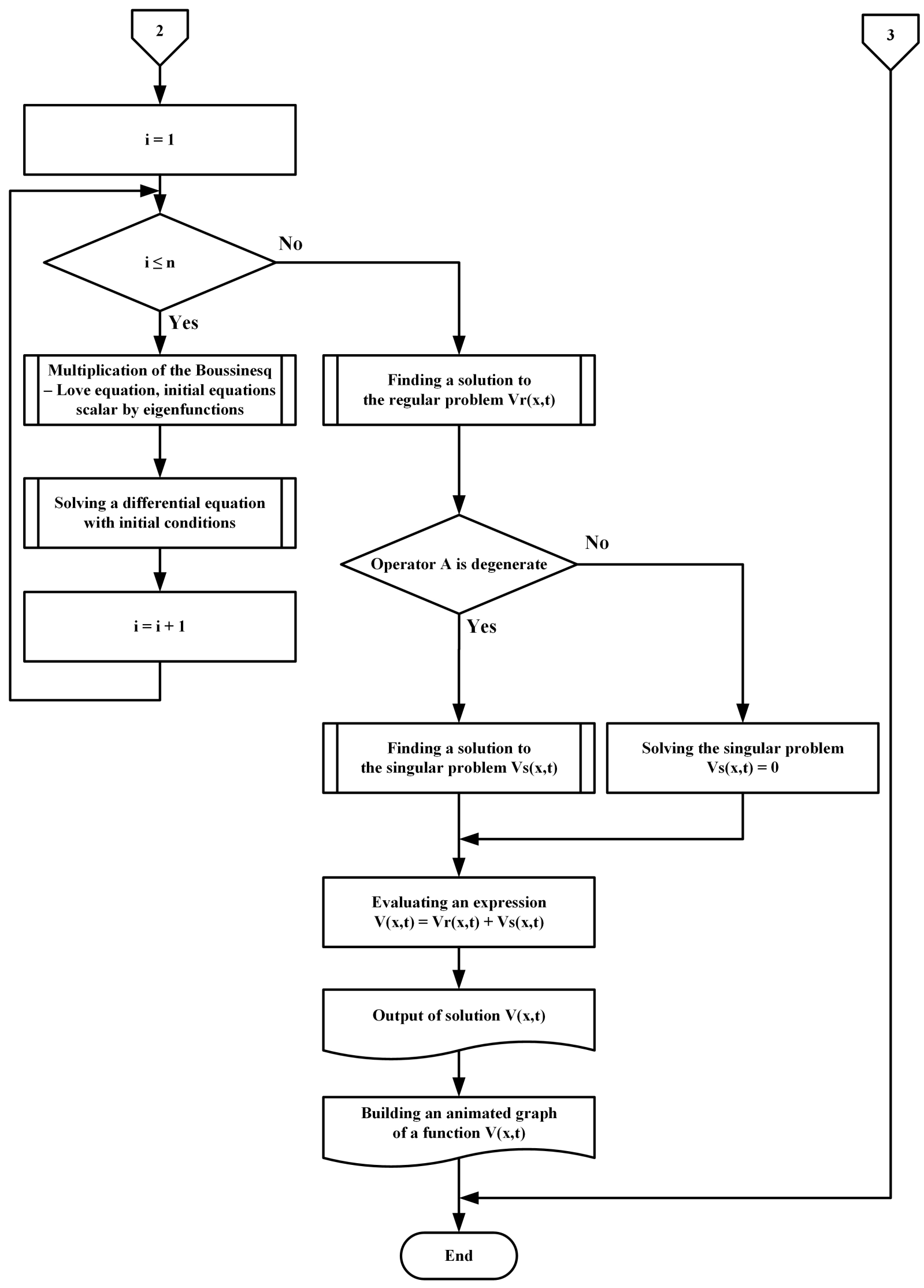

Fig. 3. Diagram of the algorithm - part 3. 
Step 5.4. Find $\lambda_{k}$ from equality to 0 of the determinant obtained at step 5.3.

Step 5.5. Find the eigenfunctions $\varphi_{k}(x)$ for the obtained at step 5.4 eigenvalues $\lambda_{k}$.

Step 5.6. Calculate the constant in the eigenfunctions $\varphi_{k}(x)$ from the normalization condition.

Step 5.7. Compose the eigenfunctions $\varphi_{i}(x)$ and the eigenvalues $\lambda_{k}$ of the Sturm Liouville problem.

Step 6. Print the obtained solution of the Sturm - Liouville problem.

Step 7. Investigate the parameter $\lambda$ of the equation for possible coincidence with the eigenvalues $\lambda_{k}$ obtained in step 5. If a match is found, then go to the next step, otherwise go to step 10.

Step 8. Check whether the number $k$, at which a match was found, is less than or equal to the previously entered value $N$. If the condition is not met, then go to the next step, otherwise go to step 10 .

Step 9. The number of terms of the Galerkin sum $n$ is equal to $k+1$, where $k$ is the number of the eigenvalue at which the coincidence was found. Go to step 11.

Step 10. The number of terms of the Galerkin sum $n$ is equal to the previously entered parameter $N$.

Step 11. Check the first three conditions of Theorem 2 on the existence of a solution. If the conditions are not met, then go to the next step, otherwise go to step 13 .

Step 12. Print "Input other parameters and initial functions". Go to step 1.

Step 13. Find the points $\mu_{k}$ of the relative spectrum of the operator pencil $\vec{B}$. Distribute $\mu_{k}$ over three lists in the cases when $\mu_{k}$ are real and different, $\mu_{k}$ are complex and $\mu_{k}$ are equal.

Step 14. Calculate the element $q_{0}(t)$ of the required function $q(t)$ by formula

$$
\begin{array}{r}
q_{0}(t)=(C \Phi(t))^{-1}\left(\Psi^{\prime \prime}(t)-C S_{0} V_{11}(t) u_{0}-C S_{1} V_{21}(t) u_{0}-C S_{0} V_{12}(t) u_{1}-\right. \\
\left.-C S_{1} V_{22}(t) u_{1}-C S_{0} \int_{0}^{t} V_{12}(t-s) h(s) d s-C S_{1} \int_{0}^{t} V_{22}(t-s) h(s) d s-C h(t)\right) .
\end{array}
$$

Step 15. Find an expression for successive approximations of the function $q(t)$ :

$$
\begin{aligned}
q[i+1](t)= & q_{0}(t)-(C \Phi(t))^{-1}\left(C S_{0} \int_{0}^{t} V_{12}(t-s) \Phi(s) q[i](s) d s+\right. \\
& \left.+C S_{1} \int_{0}^{t} V_{22}(t-s) \Phi(s) q[i](s) d s\right),
\end{aligned}
$$

Step 16. Put $i=0$.

Step 17. Calculate the first approximation $q[1](t)$ from the given initial approximation $q[0](t)=0$, using formula (14). Calculate of the estimation error ocenka, which is equal to the norm of the difference between the 1st approximation and the initial one.

Step 18. Cycle "while" ocenka $>E$. If the cycle condition is met, go to the next step, otherwise go to step 22.

Step 19. Calculate the next approximation $q[i+1](t)$ from the previous approximation $q[i](t)$ by formula (14). 
Step 20. Calculate a new estimation error ocenka, which is equal to the norm of the differences between the $i+1$-th approximation and the $i$-th.

Step 21. Increment index $i$ by one, go to step 18 .

Step 22. Print the found approximate solution $q(t)$, as well as the resulting estimation error ocenka for the found function.

Step 23. Plot the found function $q(t)$ and the functions of all obtained successive approximations.

Step 24. Check the two remaining conditions of Theorem for the found function $q(t)$ and the initial functions. If the conditions are not met, then go to the next step, otherwise go to step 26.

Step 25. Print "No solution". Stop the program.

Step 26. Represent the solution $v(x, t)$ as a Galerkin sum with found coefficients.

Step 27. Obtain the approximate solution to the Boussinesq - Love equation with the Cauchy condition using the found function $q(t)$.

Step 28. Put $i=1$.

Step 29. Cycle "while" $i \leq n$. If the cycle condition is met go to the next step, otherwise go to step 33 .

Step 30. Multiply the Boussinesq - Love equation, as well as the initial conditions obtained in Step 27, by the eigenfunction $\varphi_{i}(x)$ using inner product $\langle\cdot, \cdot\rangle$.

Step 31. Solve the second order ordinary differential equation with initial conditions.

Step 32. Increase the value of $i$ by one. Go to step 29 .

Step 33. Find the solution $u(x, t)$ to the regular problem (5)-(7).

Step 34. Check the degeneracy of the operator $A$. If the operator $A$ is non-degenerate, go to the next step, otherwise go to step 36 .

Step 35. The solution to the singular problem is equal to zero. Go to step 37.

Step 36. Find the solution $w(x, t)$ to the singular problem given by (12).

Step 37. Calculate the required function $v(x, t)$ as the sum of two previously obtained functions $u(x, t)$ and $w(x, t)$.

Step 38. Print the resulting function $v(x, t)$.

Step 39. Plot an animated graph of the function $v(x, t)$.

End of program.

\section{Computational Experiments}

Present the results of computational experiments carried out using the developed algorithm, which was implemented in the Maple software package.

Example 1. Let the parameters

$$
\lambda=-20, \lambda^{\prime}=3, \lambda^{\prime \prime}=-\frac{1}{2}, \alpha=1, \beta=-\frac{7}{32}, E=5, N=1, T=3.14, l=\pi
$$

and functions

$$
\begin{gathered}
f(x, t)=\cos (x), \quad v_{0}(x)=\cos (2 x)-1, \quad v_{1}(x)=\frac{2(\cos (2 x)-1)}{\pi}, \\
K(x)=\cos (x), \quad F(t)=-\cos (t) .
\end{gathered}
$$

Consequently, the Boussinesq - Love equation (3) takes the form

$$
(-20-\Delta) v_{t t}=(\Delta-3) v_{t}-\frac{7(\Delta+0.5) v}{32}+\cos (x) q(t),
$$


conditions (2) have the form

$$
v(x, 0)=\cos (2 x)-1, \quad v_{t}(x, 0)=\frac{2(\cos (2 x)-1)}{\pi},
$$

and the overdetermination condition

$$
\int_{0}^{\pi} v(x, t) \cos (x) d x=-\cos (t)
$$

For such parameters and initial functions, all the conditions of Theorem 2. are satisfied. Using the developed algorithm an approximate solution to the problem was found:

$$
\begin{gathered}
q(t)=-\frac{1}{15129 \pi}\left(4 7 5 0 0 \operatorname { c o s } ( t ) \left(\left(-\frac{399 \sqrt{123}}{625}+\frac{49077}{10000}\right) e^{-\frac{t(-48+\sqrt{123})}{152}}+\right.\right. \\
+\left(\frac{399 \sqrt{123}}{625}+\frac{49077}{10000}\right) e^{\frac{t(48+\sqrt{123})}{152}}+\left(\sqrt{123}-\frac{109593}{10000}\right) e^{-\frac{3 t(-16+\sqrt{123})}{152}}+ \\
+\left(\frac{2952 \sqrt{123}}{625}-\frac{45387}{1250}\right) e^{-\frac{t(-16+\sqrt{123})}{152}}+\left(-\frac{2952 \sqrt{123}}{625}-\frac{45387}{1250}\right) e^{\frac{t(16+\sqrt{123})}{152}}+ \\
+\left(-\sqrt{123}-\frac{109593}{10000}\right) e^{\frac{3 t(16+\sqrt{123})}{152}}+\left(-\frac{1968 \sqrt{123}}{625}+\frac{46617}{1250}\right) e^{-\frac{t(-16+\sqrt{123})}{76}}+ \\
\left.\left.+\left(\frac{1968 \sqrt{123}}{625}+\frac{46617}{1250}\right) e^{\frac{t(16+\sqrt{123})}{76}}-\frac{16359 e^{\frac{4 t}{19}}}{625}+\frac{30258}{625}\right)\right),
\end{gathered}
$$

reaching a possible error $4.771956378<E$ at the 4 -th step of approximation. Figures 4, 5 show the graphs of the function $q(t)$ and successive approximations.

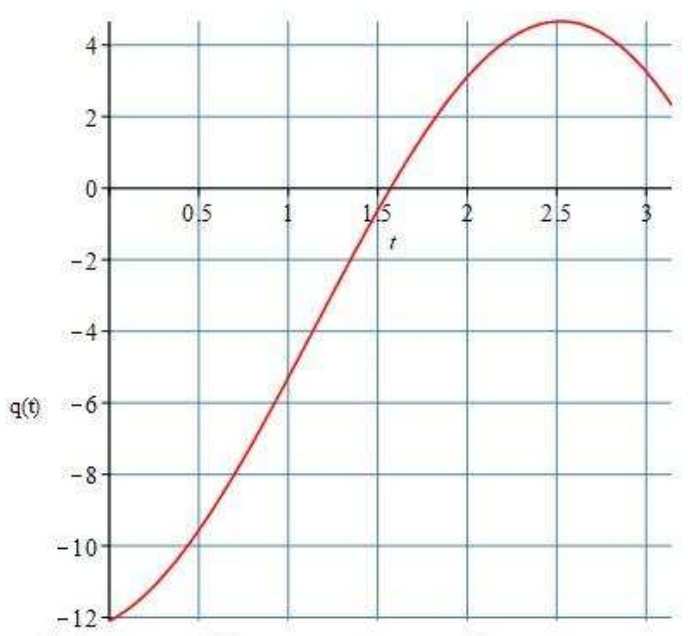

Fig. 4. Function $q(t)$ graph

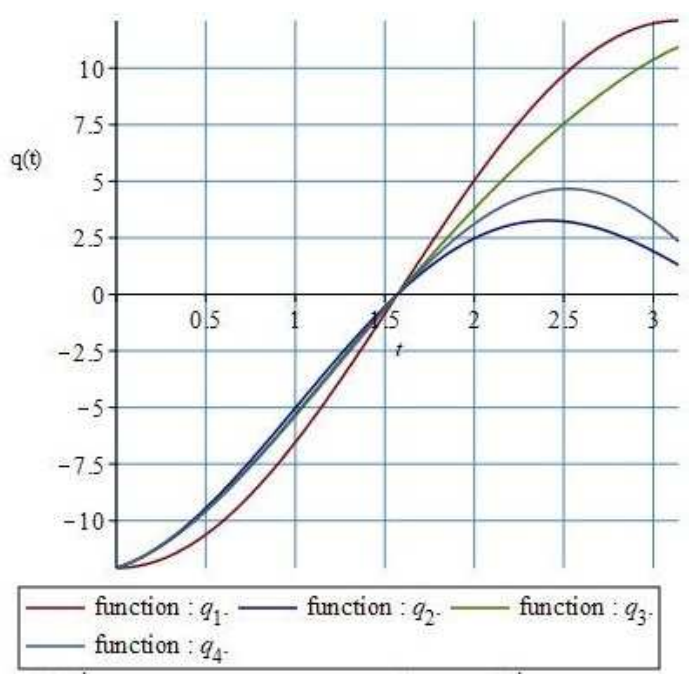

Fig. 5. Graph of functions of all approximations

Further in the program, the required function

$$
v(x, t)=\frac{\sqrt{2} \sin (x)}{\sqrt{\pi}}\left(-\frac{4 \sqrt{2}(\pi \sqrt{123}-16 \pi+304) \sqrt{123} e^{\frac{(16+\sqrt{123}) t}{152}}}{369 \pi^{\frac{3}{2}}}-\right.
$$




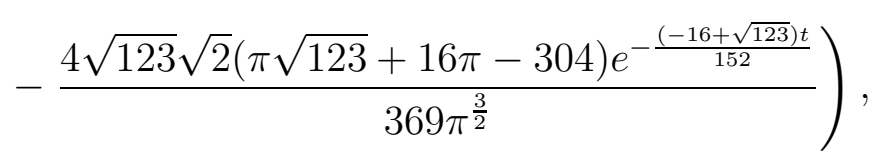

representing longitudinal vibrations in the rod was found. The last step of the program was in construction of a time-animated graph of the found function $v(x, t)$. Figures $6-9$ show the graphs of the function $v(x, t)$ at different time $t$.

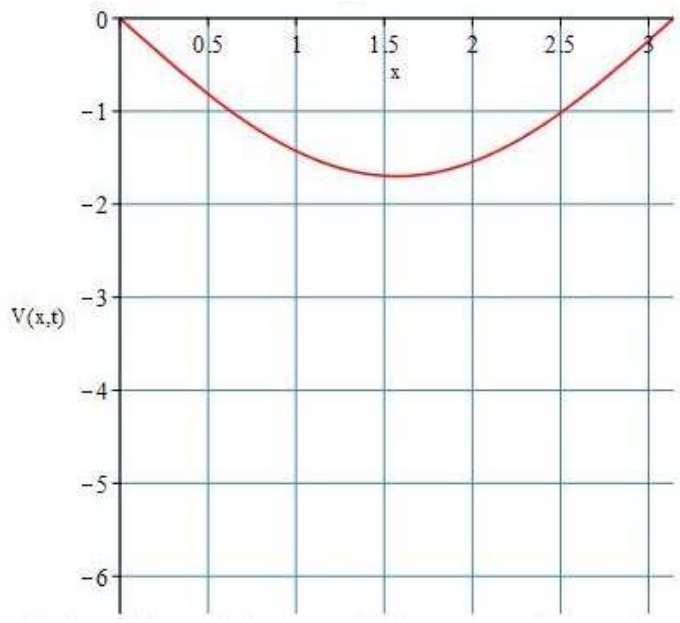

Fig. 6. Function $v(x, t)$ graph at $t=0$

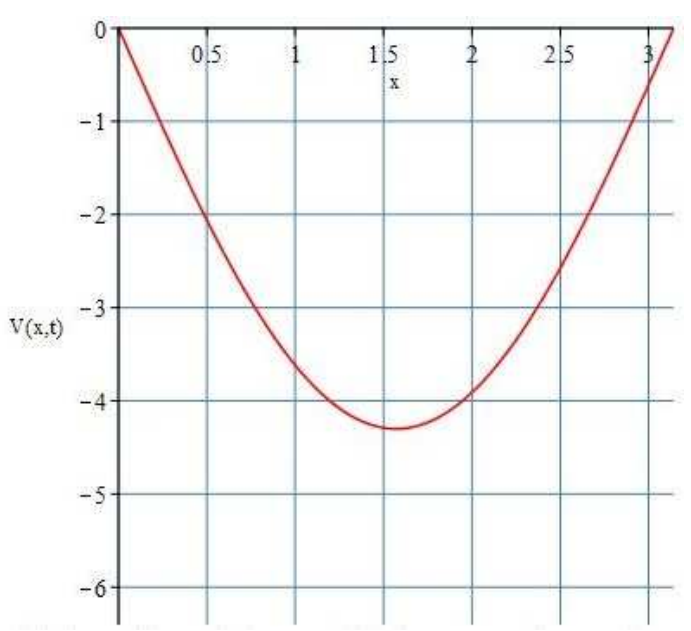

Fig. 8. Function $v(x, t)$ graph at $t=0.66$

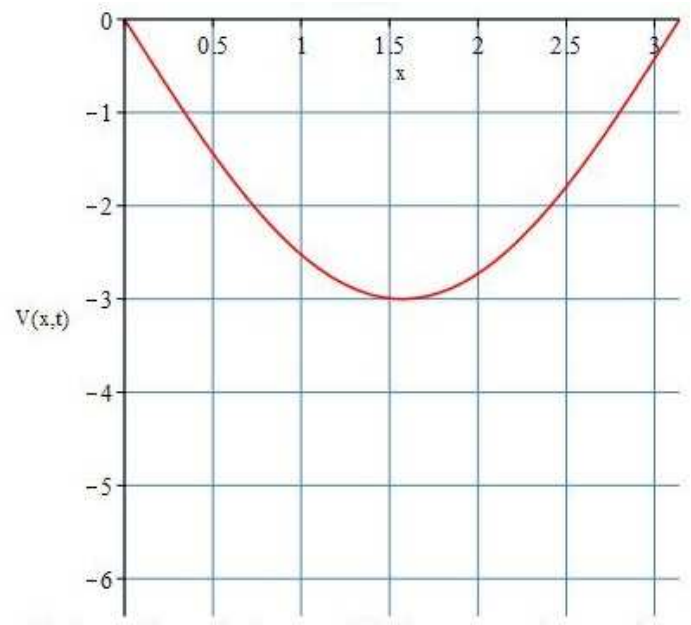

Fig. 7. Function $v(x, t)$ graph at $t=0.33$

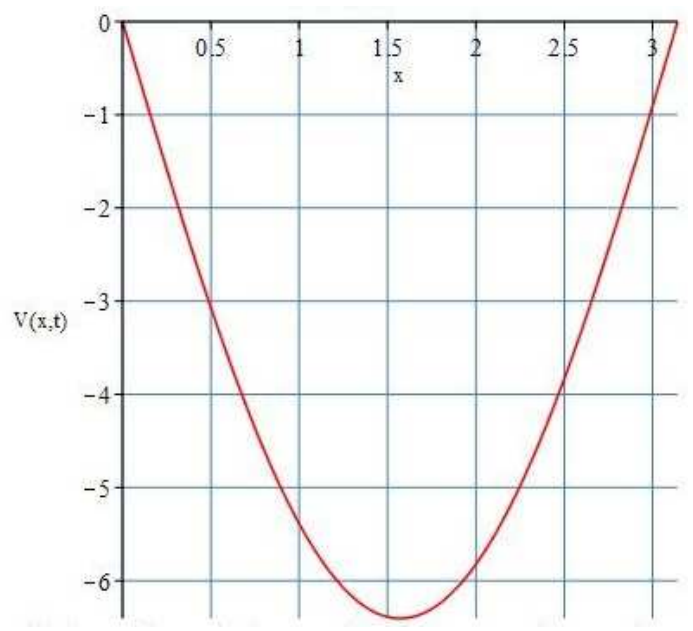

Fig. 9. Function $v(x, t)$ graph at $t=3.14$

Example 2. Let the parameters

$$
\lambda=-1, \lambda^{\prime}=-1, \lambda^{\prime \prime}=-2, \alpha=2, \beta=-2, E=4, N=2, T=1, l=\pi
$$

and functions

$$
f(x, t)=\cos (x), \quad v_{0}(x)=\sin (2 x), \quad v_{1}(x)=\sin (2 x), \quad K(x)=\cos (x), \quad F(t)=\frac{4}{3} \sin (t) .
$$


Consequently, the Boussinesq - Love equation (3) takes the form

$$
(-1-\Delta) v_{t t}=2(\Delta+1) v_{t}-2(\Delta+2) v+\cos (x) q(t),
$$

conditions (2) have the form

$$
v(x, 0)=\sin (2 x), \quad v_{t}(x, 0)=\sin (2 x),
$$

and the overdetermination condition

$$
\int_{0}^{\pi} v(x, t) \cos (x) d x=\frac{4}{3} \sin (t)
$$

With such parameters and initial functions, all conditions of Theorem 2.are satisfied. Using the developed algorithm an approximate solution to the problem was found:

$$
q(t)=\frac{(-24 \sqrt{21}+56) e^{\frac{(-3+\sqrt{21}) t}{3}}+(24 \sqrt{21}+56) e^{-\frac{(3+\sqrt{21}) t}{3}}-168 \sin (t)}{21 \pi},
$$

reaching a possible error $1.944964447<E$ at the first approximation step. Figure 10 shows the graph of the function $q(t)$.

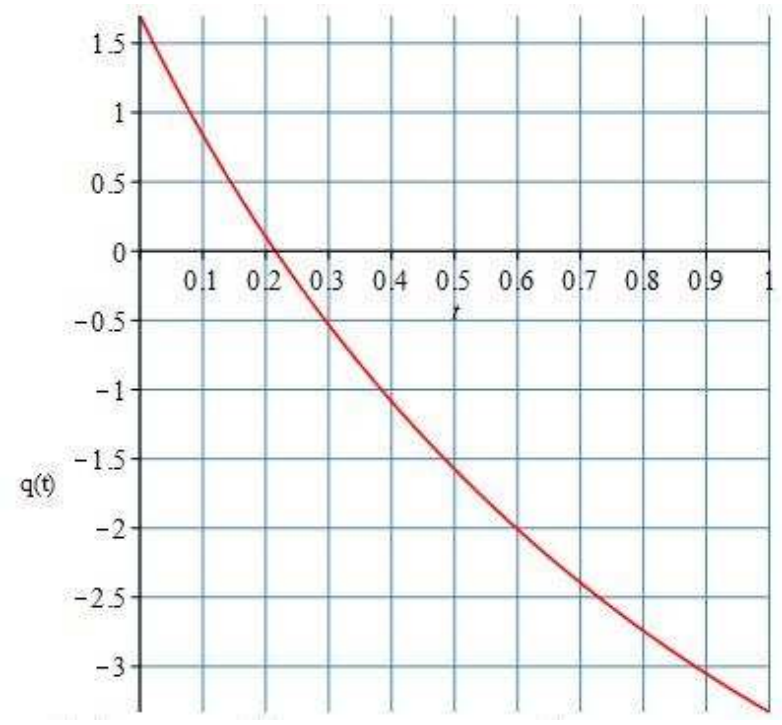

Fig. 10. Function $q(t)$ graph

Further in the program, the required function

$$
v(x, t)=V_{r}(x, t)+V_{s}(x, t)
$$

where

$$
\begin{gathered}
V_{r}(x, t)=\frac{\sqrt{2} \sin (\sqrt{4} x)}{\sqrt{\pi}}\left(\frac{64 \sqrt{2} \cos (t)}{85 \pi^{\frac{3}{2}}}+\frac{224 \sqrt{2} \sin (t)}{255 \pi^{\frac{3}{2}}}+\right. \\
+\frac{\sqrt{2} e^{-t}}{224910 \pi^{\frac{3}{2}}}\left(-63 \cosh \left(\frac{t \sqrt{21}}{3}\right)\left(-1785 \pi^{2}+5440 t+2688\right)+\right.
\end{gathered}
$$




$$
\begin{gathered}
\left.\left.+2 \sinh \left(\frac{t \sqrt{21}}{3}\right) \sqrt{21}\left(16065 \pi^{2}+19040 t-1728\right)\right)\right), \\
V_{s}(x, t)=0,
\end{gathered}
$$

was found. The last step of the program was in construction of a time-animated graph of the found function $v(x, t)$. Figures 11-14 show the graphs of the function $v(x, t)$ at different time $t$.

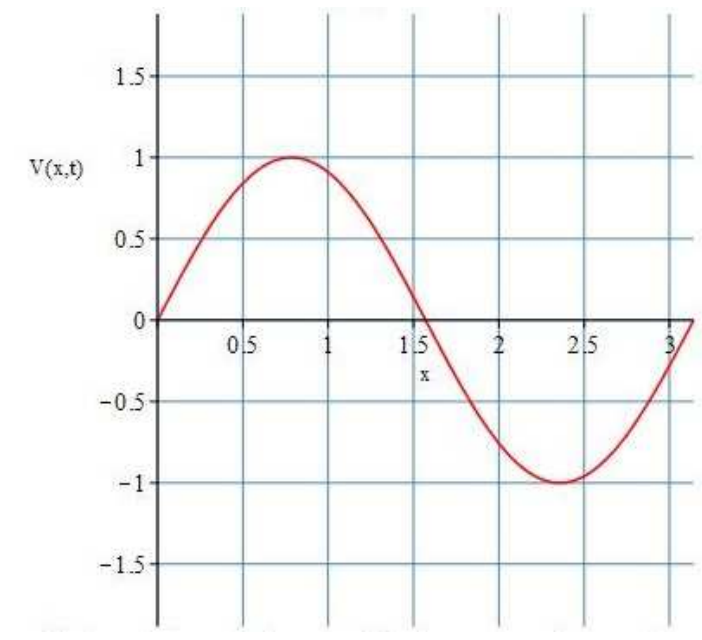

Fig. 11. Function $v(x, t)$ graph at $t=0$

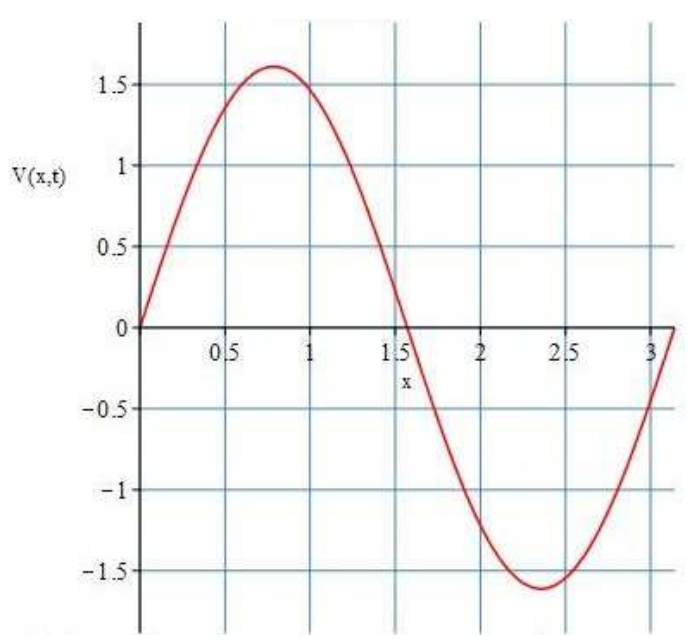

Fig. 13. Function $v(x, t)$ graph at $t=0.67$

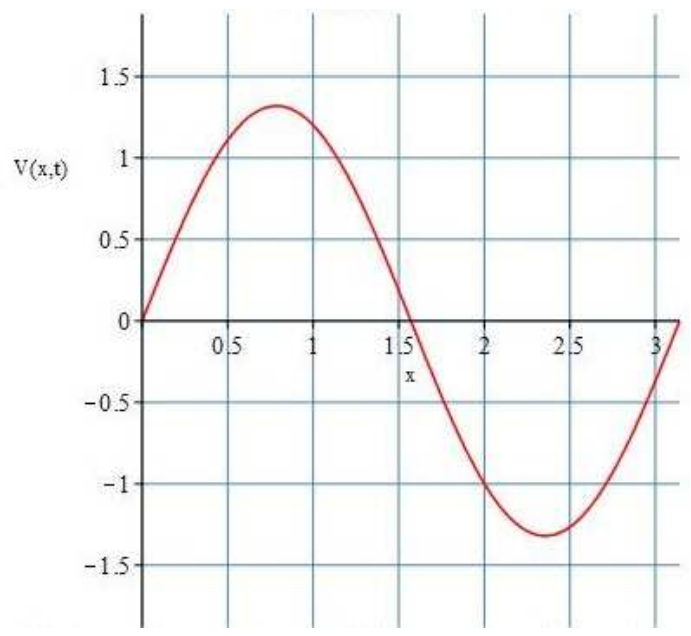

Fig. 12. Function $v(x, t)$ graph at $t=0.33$

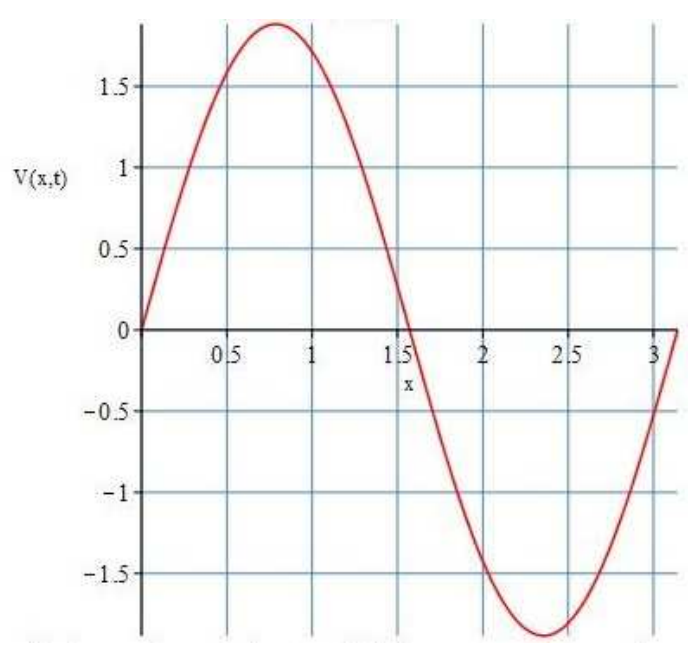

Fig. 14. Function $v(x, t)$ graph at $t=1$

The reported study was funded by RFBR, project number 19-31-9013\%.

\section{References}

1. Love A. E. H. A Treatise on the Mathematical Theory of Elasticity. Cambridge, At the University Press, 1927.

2. Zamyshlyaeva A. A., Manakova N. A., Tsyplenkova O. N. Optimal Control in Linear Sobolev Type Mathematical Models. Bulletin of the South Ural State University, 
Series: Mathematical Modelling, Programming and Computer Software, 2020, vol. 13, no. 1, pp. 5-27. DOI: $10.14529 / \mathrm{mmp} 200101$

3. Banasiak J., Manakova N. A., Sviridyuk G. A. Positive Solutions to Sobolev Type Equations with Relatively $p$-Sectorial Operators. Bulletin of the South Ural State University, Series: Mathematical Modelling, Programming and Computer Software, 2020, vol. 13 , no. 2, pp. 17-32. DOI: 10.14529/mmp200202

4. Zamyshlyaeva A. A., Lut A. V. Inverse Problem for the Boussinesq - Love Mathematical Model. Sota 2018: Semigroups of Operators - Theory and Applications. Springer Proceedings in Mathematics \& Statistics. Springer, Cham, 2020, vol. 325, pp. 427-434. DOI: 10.1007/978-3-030-46079-2_23

5. Kalinina E. A. Numerical Study of Inverse Problem of Identification of Source Density for the Two-Dimensional Non-Stationary Convection-Diffusion Equation. Dal'nevost. Mat. Zh., 2004, vol. 5, no. 1, pp. 89-99. (in Russian)

6. Vasiliev V. I., Tikhonova O. A. [Numerical Solution of the Inverse Problem for the NonStationary Configuration-Diffusion Equation]. Mathematical Notes of NEFU, 2009, vol. 16, no. 1, pp. 116-127. (in Russian)

7. Anikiev D. V., Kashtan B. M., Blagoveshchensky A. S., Mulder V. A. [Exact Dynamic Method for Solving the Inverse Problem of Seismic Based on the Integral Equations of Gelfand - Levitan]. Scientific notes of St. Petersburg State University. Geophysical issues, 2011, no. 44, pp. 49-81. (in Russian)

8. Puzynina T. P., Thach V. T. On Numerical Solution of Direct and Inverse Scattering Problems for Spherically Symmetric Potentials Dependingon Parameters. Bulletin of Peoples' Friendship University of Russia. Series Mathematics. Informationsciences. Physics, 2012, no. 4, pp. 73-86. (in Russian)

9. Zamyshlyaeva A. A., Lut A. V. Numerical Investigation of the Boussinesq - Love Mathematical Models on Geometrical Graphs. Bulletin of the South Ural State University, Series: Mathematical Modelling, Programming and Computer Software, 2017, vol. 10, no. 2, pp. 137-143. DOI: 10.14529/mmp170211

Aleksander V. Lut, Postgraduate Student, Department of Applied Mathematics and Programming, South Ural State University (Chelyabinsk, Russian Federation), lutav@susu.ru.

Received August 14, 2020. 


\title{
ЧИСЛЕННОЕ ИССЛЕДОВАНИЕ ОБРАТНОЙ ЗАДАЧИ ДЛЯ МАТЕМАТИЧЕСКОЙ МОДЕЛИ БУССИНЕСКА - ЛЯВА
}

\author{
A. B. Лym
}

\begin{abstract}
Статья посвящена численному исследованию обратной задачи для математической модели Буссинеска - Лява, описывающей продольные колебания в тонком упругом стержне с учетом инерции и при внешней нагрузке. Под обратной задачей понимается восстановление какого-либо коэффициента исходного уравнения, в данном случае функции отвечающей за внешнюю нагрузку. Для ее нахождения использовался метод последовательных приближений. В первом параграфе представлены полученные ранее результаты аналитического исследования данной задачи. Во втором параграфе описывается по шагам алгоритм нахождения приближенного решения. Третий параграф содержит результаты проведения вычислительных экспериментов, представленных двумя примерами. Приведенные примеры получены в ходе реализации разработанного алгоритма в программном пакете Maple. Результаты данной работы могут быть использованы в дальнейших исследованиях в области математической физики или математического моделирования.

Ключевые слова: математическая модель; уравнение Буссинеска - Лява; обратная задача; численное исследование; уравнение соболевского типа; метод последовательных приближений.
\end{abstract}

\section{Литература}

1. Ляв, А. Математическая теория упругости / А. Ляв. - М.-Л.: ОНТИ. - 1935.

2. Замышляева, А. А. Оптимальное управление в линейных математических моделях соболевского типа / А. А. Замышляева, Н. А. Манакова, О. Н. Цыпленкова // Вестник ЮУрГУ. Серия: Математическое моделирование и программирование. 2020. - T. 13, № 1. - C. 5-27.

3. Банасяк, Я. Позитивные решения уравнений соболевского типа с относительно p-секториальным оператором / Я. Банасяк, Н. А. Манакова, Г. А. Свиридюк // Вестник ЮУрГУ. Серия: Математическое моделирование и программирование. 2020. - T. 13, № 2. - C. 17-32.

4. Zamyshlyaeva, A. A. Inverse Problem for the Boussinesq - Love Mathematical Model / A. A. Zamyshlyaeva, A. V. Lut // Sota 2018: Semigroups of Operators - Theory and Applications. Springer Proceedings in Mathematics \& Statistics. - Springer, Cham, 2020. - V. 325, P. 427-434.

5. Калинина, Е. А. Численное исследование обратной задачи восстановления плотности источника двумерного нестационарного уравнения конвекции-диффузии / Е. А. Калинина // Дальневосточный математический журнал. - 2004. - Т. 5, № 1. - C. 89-99.

6. Васильев, В. И. Численное решение обратной задачи для нестационарного уравнения конфекции-диффузии / В. И. Васильев, О .А. Тихонова // Математические заметки СВФУ. - 2009. - Т. 16, № 1. - С. 116-127. 
7. Аникиев, Д. В. Точный динамический метод решения обратной задачи сейсмики на основе интегральных уравнений Гельфанда - Левитана / Д. В. Аникиев, Б. М. Каштан, А. С. Благовещенский, В. А. Мулдер // Ученые записки СПбГУ. Вопросы геофизики. - 2011. - № 44. - С. 49-81.

8. Пузынина, Т. П. О численном решении прямой и обратной задачи рассеяния на сферически симметричных потенциалах, зависящих от параметров / Т. П. Пузынина, Во Чонг Тхак // Вестник РУДН. Серия: Математика. Информатика. Физика. - 2012. - № 4. - С. 73-86.

9. Замышляева, А. А. Численное исследование математических моделей Буссинеска - Лява на геометрических графах / А.А. Замышляева, А.В. Лут // Вестник ЮУрГУ. Серия: Математическое моделирование и программирование. - 2017. T. 10, № 2. - C. 137-143.

Лут Александр Валерьевич, аспирант, кафедра прикладной математики и программирования, Южно-Уральский государственный университет (г. Челябинск, Российская Федерачия), lutav@susu.ru.

Поступила в редакиию 14 августа 2020 г. 